\title{
Autonomous Neurobiological Pathways to Late-Life Major Depressive Disorder: Clinical and Pathophysiological Implications
}

Anand Kumar, M.D., Jim Mintz, Ph.D., Warren Bilker, Ph.D., and Gary Gottlieb, M.D., M.B.A.

The objective of our study was to elucidate distinct paths to depression in a model that incorporates age, measures of medical comorbidity, neuroanatomical compromise, and cognitive status in a sample of patients with late-life major depressive disorder (MDD) and nondepressed controls. Our study was cross-sectional in nature and utilized magnetic resonance imaging (MRI) estimates of brain and highintensity lesion volumes together with clinical indices of cerebrovascular and nonvascular medical comorbidity. Neuroanatomic and clinical measures were incorporated into a structural covariance model in order to test pathways to $M D D$. Our data indicate that there are two paths to MDD; one path is represented by vascular and nonvascular medical comorbidity that contribute to high-intensity lesions that lead to depression. Smaller brain volumes represent a distinct path to the mood disorder. Age influences depression by increasing atrophy and overall medical comorbidity but has no direct impact on MDD. These findings demonstrate that there are distinct biological substrates to the neuroanatomical changes captured on MRI. These observations further suggest that neurobiological mechanisms acting in parallel may compromise brain structure/function, thereby predisposing individuals to clinical brain disorders such as depression.

[Neuropsychopharmacology 26:229-236, 2002] (C) 2002 American College of Neuropsychopharmacology. Published by Elsevier Science Inc.
KEY WORDS: Late-life depression; Major depression; Magnetic resonance imaging; High-intensity lesions; Atrophy; Path analysis

Clinically significant mood disorders are among the most common psychiatric illness in the elderly (Blazer et al. 1987; Parmalee et al. 1992; Henderson et al. 1997). They increase psychosocial and economic morbidity and contribute to the relatively high rate of suicide in the elderly (Stewart et al. 1989; Wells et al. 1989; Unutzer et al. 1997;

From the Neuropsychiatric Institute, UCLA School of Medicine, Los Angeles, CA (AK, JM);Department of Biostatistics and Epidemiology, University of Pennsylvania School of Medicine, Philadelphia, PA (WB); and Massachusetts General Hospital, Harvard Medical School, Boston, MA (GG).

Address correspondence to: Anand Kumar, M.D., 37-384 B, Neuropsychiatric Institute 760 Westwood Plaza, UCLA School of Medicine, Los Angeles, CA 90024; E mail: akumar@mednet.ucla.edu.

Received March 13, 2001; revised June 29, 2001; accepted July 6, 2001.

Online publication: $7 / 12 / 01$ at www.acnp.org/citations/ Npp071201150.
Penninx et al. 1999). Depression in the elderly is consistently associated with medical illness, and this relationship has been observed in virtually all clinical settings including acute, long-term care, and ambulatory programs (Coulehan et al. 1990; Lustman et al. 1992; Caine et al. 1993; Gierz and Jeste 1993; Katz et al. 1994; Lacro and Jeste 1994; Frasure-Smith et al. 1995; Katz 1996; Borson et al. 1998). Depression is associated with a broad spectrum of medical disorders including cardiovascular, cerebrovascular, musculoskeletal, metabolic, and pulmonary illnesses and malignancies (Coulehan et al. 1990; Lustman et al. 1992; Caine et al. 1993; Gierz and Jeste 1993; Katz et al. 1994; Lacro and Jeste 1994; Frasure-Smith et al. 1995; Katz 1996; Zubenko et al. 1997; Borson et al. 1998). Acknowledging this robust connection between medical disorders and depression, the National Institutes of Health consensus conference on depression in late life concluded, "The hallmark of depression in the elderly is its association with medical comorbidity"(National Insti- 
tutes of Health 1992). Despite these observations, the precise nature of the relationship between mood and medical disorders and the pathways that lead from medical illness to clinical depression remain elusive.

The application of magnetic resonance imaging (MRI) to the study of late-life depression has provided information on the neuroanatomical substrates of depression (Rabins et al. 1991; Coffey et al. 1993; Krishnan 1993; Sheline et al. 1996; Kumar et al. 1997a, 1997b, 1998; Lai et al. 2000). Late-life depression is associated with smaller focal brain volumes together with increased MRI-determined high-intensity lesion in the brain (areas that appear bright on T2 and proton density weighted images) when compared with nondepressed controls. The decreases in brain volume appear to be relatively focal and have been described in the prefrontal lobe, hippocampus, and the caudate nucleus (Krishnan 1993; Sheline et al. 1996; Kumar et al. 1998). The high-intensity lesions are also distributed in the neocortical and subcortical areas. The increased prevalence of high-intensity lesions in the brain together with their putative relationship to vascular disease in some samples has led to a resurgence of interest in the role of vascular mechanisms in the pathophysiology of late-life major depression (Morris and Rapoport 1990; Alexopoulos et al. 1997; Krishnan et al. 1997). However, the mechanisms by which lesions and vascular disease influence mood disorders remain unknown, and the relative importance of high-intensity lesions in the neocortical areas versus the basal ganglia remain unclarified (Sato et al. 1999; Steffens et al. 1999). A recent report from the Cardiovascular Health Study, a large community-based epidemiological study, also suggested that the impact of cardiovascular disease and lesions on depressive symptoms may be mediated by the subject's cognitive status and the level of functional activity (Sato et al. 1999).

We recently demonstrated that atrophy and highintensity lesions increased the statistical odds (odds ratio) of developing major depressive disorder in the elderly (late-life MDD) (Kumar et al. 2000). Smaller frontal lobe volumes and larger whole-brain high-intensity lesion volumes appeared to independently increase the odds of developing late-life MDD in our study (see Table 1 ). The purpose of our current study was to further examine specific pathways that may lead from cerebrovascular risk factors, nonvascular medical burden, age, and atrophy to late-life MDD and thereby construct a more holistic model of the pathophysiology of late-life depression. Based on our earlier correlations and relationships observed between clinical and neuroimaging measures, we developed an a priori model of pathways to MDD. We hypothesized that vascular and nonvascular medical comorbidity contribute to high-intensity lesions in the brain that lead to MDD. This would represent one pathway to MDD. Smaller brain volume in the frontal lobes would represent a distinct path to late-life MDD independent of medical comorbidity. To examine the role of cognitive status in the paths to MDD, we additionally hypothesized that in our MDD sample, cognitive state would be secondary to the primary mood state, and the path would lead from MDD to cognitive compromise.

\section{MATERIALS AND METHODS}

\section{Patients and Methods}

Our samples were comprised of 51 patients with MDD and 30 nondepressed controls and have been recently reported on (Kumar et al. 2000). All patients diagnosed with depression met DSM IV criteria for MDD (American Psychiatric Association 1994) and had a score of 15 or greater on the 17-item Hamilton Depression Rating Scale (Hamilton 1967). Patients were recruited from the inpatient and ambulatory geropsychiatry programs at the University of Pennsylvania Medical Center. After complete description of the study to the subjects, written informed consent was obtained. MDD patients had several stable comorbid medical disorders but were free of other disorders of the central nervous system. Patients and controls received thorough medical and neurologic exams and laboratory tests that included complete and differential blood counts, electrolytes, hepatic and renal screens, thyroid, and serology studies. None of the subjects had a history or mental status exam that was consistent with clinical dementia and all had mini mental state exam (MMSE) scores in the normal range (Folstein et al. 1975). The MMSE served as the marker of cognitive state in the current analyses.

The Cumulative Illness Rating Scale (CIRS), which is a 12-item organ system-based instrument, was used to estimate medical burden in patients and controls (Linn et al. 1968). Organ dysfunction is rated on a $0-4$ severity scale for 12 organ systems, such as cardiac, vascular, gastrointestinal, endocrine, and genitourinary. In order to independently evaluate the impact of vascular and nonvascular disorders on MDD, we developed a composite estimate of noncardiovascular medical burden by summing the 10 noncardiovascular components of the Noncardiovascular (NCRDV) of the Cumulative Illness Rating Scale (CIRS). The American Heart Association Stroke Risk Prediction Chart was used to quantify cerebrovascular risk factor (CVRF) burden in all subjects (American Heart Association 1990; Wolf et al. 1991). This composite index comprises eight factors-age, systolic blood pressure, treatment of hypertension, diabetes, smoking, ischemic heart disease, atrial fibrillation, and left ventricular hypertrophy. In our analysis, the composite CVRF score reflects the total score minus the points attributable to age. This approach permits us to concurrently assess the role of both cerebrovascular risk factors and nonvascular medical illness in late-life MDD more precisely. The impact of age on clinical and neuroimaging measures and MDD was independently assessed. Details on our clinical methods, including inclusion and exclusion criteria, have been recently published (Kumar et al. 2000). 
MR images were obtained on a 1.5 Tesla GE Signa scanner with head coil. T2 and proton density weighted images were obtained (TR $=3000, \mathrm{TE}=30$ and 60 $\mathrm{msec}$ ). Slices were $5 \mathrm{~mm}$ contiguous, field of view was $22 \mathrm{~cm}$, and all images were displayed on a $256 \times 256$ matrix. Anatomical boundaries used to demarcate regional lobar boundaries and our segmentation methods have been previously described (Cowell et al. 1994). The fuzzy connectedness approach was used to quantify whole-brain high-intensity lesion volume in MR images. Frontal lobe and whole-brain high-intensity lesion volumes were normalized to total intracranial volume for our analysis (Udupa and Samarasekera 1996).

\section{Statistical Methods}

The path analyses were performed using Mplus (Version 1.03; Muthen 1984; www.statmodel. com), a general modeling program. We used a structural equation approach that permitted simultaneous evaluation of the multistage causal models that were of interest. Mplus permits specification of a categorical dependent variable (depression diagnosis). Principal interest centered on the multilevel path model suggested by our previous work. We also evaluated several alternative models in which additional paths were added to determine if any significant improvement on the primary model was possible. The path coefficients between continuous variables are conventional regression coefficients that indicate how much change is predicted for a unit change in the causal variable. The path coefficients to the categorical outcome are probit regression coefficients that indicate the strengths of the relationship between the predictive variable and the probability of group membership. To facilitate interpretation of the coefficients, the brain measures were rescaled. Normalized frontal lobe volume (absolute volume divided by total intracranial volume) was multiplied by a factor of 100, and normalized lesion volume was multiplied by a factor of 1000 . These simple transformations rescaled the coefficients to a more readable format without changing any of the statistical results.

We also explored the role of cognitive state/compromise in two different modifications of the primary model. The mean MMSE was used as the marker of cognitive status. First, we evaluated the fit of a model that postulated that cognitive status was a result of high-intensity lesions and an intermediate or mediating variable in the diagnosis of depression. This model was suggested by a recent report that examined the relationship between depressive symptoms, structural brain changes, and cognition (Sato et al. 1999). Second, we evaluated a model that instead posited that cognitive status was a result rather than a cause of depression. These alternative models are not nested, so formal testing of the superiority of one over the other was not possible. However, we compared the relative indices of goodness of fit, parsimony, and plausibility of both models. For models of interest, we report the goodness-of-fit $\chi^{2}$ and degrees of freedom as reported by Mplus for the estimated models, path coefficients, and standard errors. The specifics of the models that were evaluated are presented in Results. For convenience, we refer to the path coefficients as $\beta$, the standard errors as $\mathrm{SE}$, and the ratio of these as $\mathrm{z}$. As a rough guide to statistical significance of the paths, this ratio of the path coefficient to its standard error was referred to the normal curve; the resultant two-tailed probability is reported as $p$.

\section{RESULTS}

The initial model tested is as depicted in Figure 1 but also included direct paths from age to CVRF $(\beta=0.076$; $\mathrm{SE}=$ $0.065 ; \mathrm{z}=1.17 ; p=.24)$ and to lesions $(\beta=0.114 ; \mathrm{SE}=$ $0.076 ; z=1.51 ; p=.13$ ) (Figure 2, model A). Neither of these paths was significant, so the model was reevaluated without them. Goodness-of-fit $\chi^{2}$ for the primary model (Figure 1) was 3.92 with $\mathrm{df}=7(p=.79)$, indicating that the model was statistically plausible. The relevant statistical data are incorporated into Figure 1. All of the path coefficients were large relative to their standard errors.

Subsequent analyses tested a variety of alternative specifications (Figure 2). One of these included direct paths from age to $\operatorname{MDD}(\beta=0.02 ; \mathrm{SE}=0.03 ; \mathrm{z}=0.75$; $p=.46)$ and direct paths from $\mathrm{CVRF}(\beta=-0.027$; $\mathrm{SE}=$ $0.046 ; \mathrm{z}=-0.59 ; p=.55)$ and nonvascular medical comorbidity $(\beta=0.021 ; \mathrm{SE}=0.104 ; \mathrm{z}=0.204 ; p=0.84)$ to MDD (Figure 2, model B). Another model included a path from lesions to atrophy $(\beta=0.01 ; \mathrm{SE}=0.04 ; \mathrm{z}=$ $0.31 ; p=.76)$. Addition of these various nonsignificant paths did not alter the direction or magnitude of the coefficients in the final model to any appreciable degree, and the causal paths from both brain measures to MDD diagnosis remained large and significant. Similarly, the addition of paths from nonvascular medical comorbidity $(\beta=0.007 ; \mathrm{SE}=0.10 ; \mathrm{z}=0.076 ; p=.94)$ and $\mathrm{CVRF}(\beta=$ $0.01 ; \mathrm{SE}=0.05 ; \mathrm{z}=0.18 ; p=.86$ ) to atrophy were not significant and did not alter the significance of any of the results as summarized in Figure 1 (Figure 2, model C).

Additional analyses were performed to explore the role of cognitive status in the explanatory model. The mean MMSE was used as the index of the cognitive state. One model postulated that cognitive status was a mediating variable, resulting from lesions and causing MDD. Initial estimation of this model indicated a very poor fit $\left(\chi^{2}=32.86, \mathrm{df}=9, p<.0001\right)$. Inspection of the modification indices indicated that this model did not adequately account for the covariance between MMSE and nonvascular comorbidity. When an additional direct path from noncardiovascular comorbidity to MMSE was added, the resulting model did fit well (goodness-of-fit $\chi^{2}=6.75 ; \mathrm{df}=$ $8 ; p=.56$ ). The direct path from cognitive state to MDD was significant $(\beta=-0.256, \mathrm{SE}=0.056, \mathrm{z}=-4.59, p<$ .001). Paths from both brain measures to MDD remained 


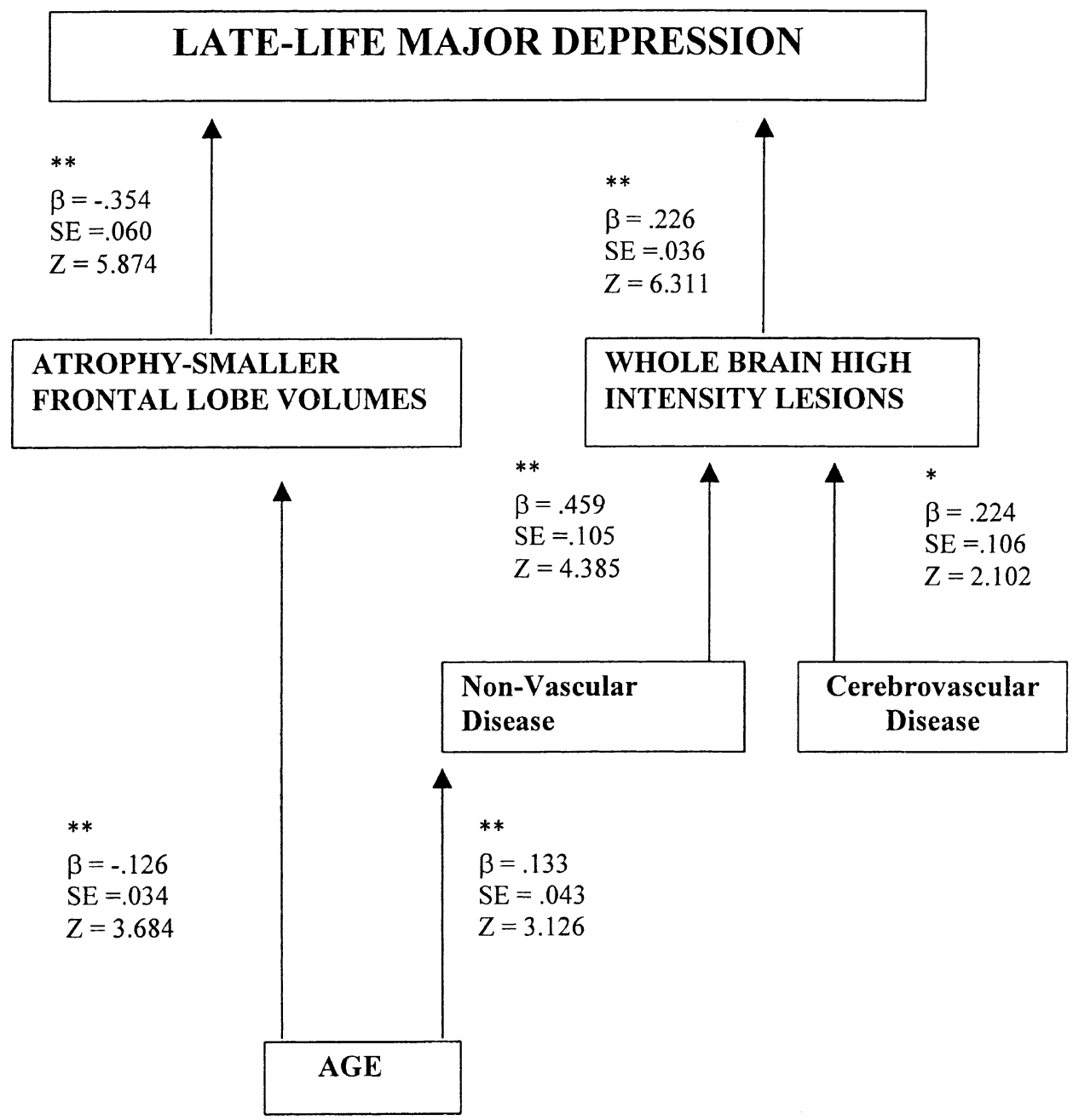

Figure 1. The primary model and pathways to major depression. $\beta$, path coefficients; SE, standard error; $Z$, ratio of path coefficients/standard error; ${ }^{*} p, .036 ;{ }^{* *} p=.002$. significant as well. This suggests that lesions have a causal role in MDD over and above any cognitive effects they may induce. We then evaluated an alternative model that posited that the cognitive status (MMSE) was a result rather than a cause of MDD. As detailed above, it was necessary to include the direct path from nonvascular comorbidity to MMSE to obtain an acceptable overall fit (goodness-of-fit $\chi^{2}=4.51, \mathrm{df}=8, p=.80$ ). This model ap-

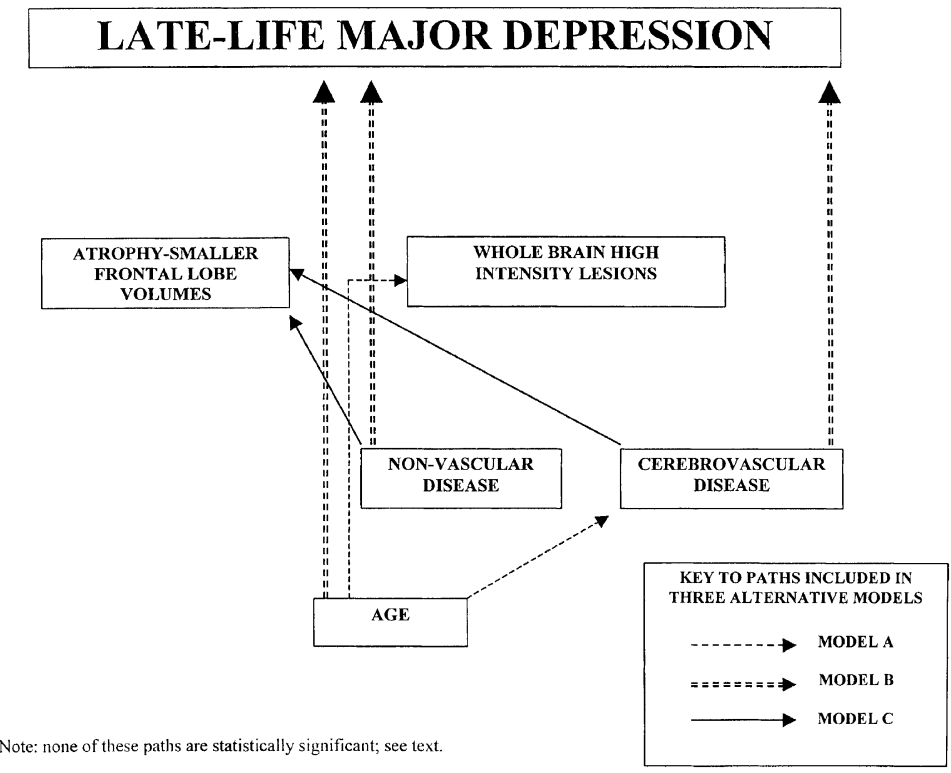

Figure 2. Additional pathways tested in three alternate models. None of these paths are statistically significant; see text. 
Table 1. The Primary Demographic, Clinical, and Neuroanatomic Measures in the MDD and Control Groups

\begin{tabular}{lcc}
\hline Index & MDD $^{a}$ & Controls $^{b}$ \\
\hline Age & $74.3^{*}$ & 69.43 \\
& $(6.56)$ & $(6.09)$ \\
MMSE & $27.4^{*}$ & 29.54 \\
& $(2.53)$ & $(0.69)$ \\
NCRDV-CIRS & $2.98^{*}$ & 1.08 \\
& $(2.75)$ & $(1.75)$ \\
CVRF & 6.19 & 5.32 \\
& $(3.71)$ & $(3.10)$ \\
Ham D & 19.8 & $\mathrm{~N} / \mathrm{A}$ \\
& $(3.91)$ & 0.167 \\
Frontal brain/CV & $0.148^{*}$ & $(0.0162)$ \\
& $(0.0173)$ & 0.00037 \\
Lesion/CV & $0.0033^{*}$ & $(0.00054)$ \\
& $(0.0046)$ & \\
\hline
\end{tabular}

${ }^{a} n=51 ; 36$ females, 15 males.

$b_{n}=30 ; 23$ females, 7 males.

${ }^{*} p=.05$ when compared with controls, by $t=$ test.

The table presents some of the primary clinical and demographic characteristics for the MDD and control groups. MMSE, Mean Mini Mental State Exam scores; NCRDV-CIRS, Non Cardiac/Vascular Components of Cumulative Illness Rating Scale score; CVRF, Cerebrovascular Risk Facto Scale score (without age); CV, intracranial volume; N/A, not applicable.

peared to be preferable. It had a slightly better goodnessof-fit index and required estimation of one less parameter. Thus, it was more parsimonious than the model that postulated that cognitive status was a cause of MDD without sacrificing goodness of fit. Paths from atrophy and lesions to MDD remained highly significant in all models that incorporated cognitive status.

\section{DISCUSSION}

In this study, we elaborate on our earlier observations and incorporate the relationships between several salient clinical and neurobiological measures into a holistic model of the pathophysiology of late-life MDD. Our data indicate that there are two distinct paths to late-life MDD. Nonvascular and vascular medical comorbidity contributing to high-intensity lesions that in turn lead to MDD represents one path. Smaller frontal lobes, as a marker of neuronal atrophy, represent another path to MDD. Both cerebrovascular and nonvascular medical burden exert no influence on frontal lobe volume, thereby suggesting that atrophy may reflect a neurobiological path that is distinct from the cumulative effects of medical insults to the central nervous system (CNS). In our model, age had a direct influence on frontal brain volume and an indirect influence on lesions mediated by nonvascular medical disorders. Those mediating paths accounted for the association between increasing age and the risk of MDD. Age per se had no direct impact on MDD in our study.

Smaller brain volumes, estimated using in vivo MR imaging, have been identified in the prefrontal, mesial tempo- ral, and subcortical areas in patients with MDD when compared with controls (Kumar et al. 2000). In general, the prefrontal region has been more consistently implicated in the pathophysiology of psychiatric disorders. Postmortem neuropathological reports also demonstrate structural changes in the prefrontal regions in brain tissue obtained from patients who were diagnosed with MDD when compared with controls (Duman and Charney 1999; Rajkowska et al. 1999; Rajkowska 2000). These changes include decreases in cortical thickness and neuronal size together with reductions in neuronal and glial density (Duman and Charney 1999; Rajkowska et al. 1999). Although the etiology of these neuronal changes is unknown, genetic and other neurobiological explanations have been offered to explain these sets of observations (Duman and Charney 1999; Rajkowska et al. 1999; Sheline 2000). Stress and clinical depression are often associated with hypercortisolemia, which has neurotoxic properties (Sapolsky and Pulsinelli 1985). It has been suggested that stress-induced reductions in neurotrophins may also play a role in the structural changes observed in patients with MDD (Duman and Charney 1999). A complex set of interrelated neurobiological events may constitute the path that leads from smaller frontal brain volume to late-life MDD (Gould et al.1998; Lopez et al. 1998). In this study, we emphasize the principal medical/neuronal pathways that lead to MDD. However, at a cellular level, each principal pathway is likely to be composed of smaller paths and components, each with its distinctive biological characteristics (Gould et al. 1998; Lopez et al. 1998; Duman and Charney 1999).

MDD is also characterized by an increase in MRI-determined high-intensity lesions in neocortical and subcortical areas. The apparent link of these lesions to vascular disease has led to speculation that the presence of these lesions suggests an underlying etiology that is predominantly vascular in origin (O'Brien et al. 1996; Krishnan et al. 1997; Hickie and Scott 1998) The neuropathological correlates of high-intensity lesions are diverse and include areas of white matter ischemia, edema, demyelination, and perivascular spaces in the neocortical and subcortical areas of the brain (Awad et al. 1986; Braffman et al. 1988; Drayer 1988; Spangler et al. 1994; Ylikoski et al. 1995). Our data indicate that vascular and nonvascular comorbidity contribute to these lesions. It should be emphasized that vascular and nonvascular comorbidity together account for $\sim 25 \%$ of the variance in lesion volumes in our sample, thereby suggesting that other unknown biological factors also contribute substantially to these lesions that are captured as high-intensity areas on MR images (Ylikoski et al. 1995). Furthermore, whereas the cerebrovascular risk factors examined in our study primarily reflect macrovascular disease, it is likely that compromise to the microvasculature, secondary to disorders such as diabetes, also plays an important role (Lyness et al. 1998). Impairments in brain oxygenation, secondary to chronic obstructive pulmonary disease (COPD), and a combination of disease 
processes/mechanisms may, under the rubric of "nonvascular medical comorbidity," collectively contribute to the pathophysiology of these lesions (Borson et al. 1998). Their origins are therefore likely to be multifactorial, with vascular injury representing an important, though not exclusive, contributing factor.

A recent report from the Cardiovascular Health Study drew the conclusion that a decrease in cognitive status, as measured by a modified version of the MMSE, served as an intermediate step between neocortical lesions and mood symptoms (Sato et al. 1999). In our study sample, the alternative model, which posited that cognitive impairments are a consequence or associated feature of MDD, was a somewhat better fit for our data. In any case, none of these competing models affected conclusions regarding the direct path between brain anatomical compromise and MDD. The direct effects of lesions on MDD cannot be accounted for by the presumed effects of lesions on cognition. Conversely, the effects on cognition could be explained as the results of MDD. Cognitive changes are frequently encountered clinically in elderly patients with a mood disorder (Emery and Oxman 1992; Alexopoulos et al. 1993). The relationship between mood and cognition, especially in the elderly, is both complex and dynamic (Alexopoulas et al. 1993, 2000). Longitudinal data incorporating the impact of treatment on both sets of measures are needed in order to make a more definitive statement (Alexopoulas et al. 1993, 2000).

Prevalence estimates of MDD are lower in the elderly when compared with non-elderly adult samples (Blazer et al. 1987). Our findings clarify how age influences MDD. They suggest that the neuronal and medical consequences of increasing age contribute to both smaller regional brain volumes and greater high-intensity lesions, which in turn lead to MDD. Therefore, whereas age per se has no deleterious impact on mood, the overall biological/medical correlates of aging compromise brain structure, thereby predisposing individuals to clinically significant mood disturbances.

A few limitations of our current analysis and report need to be acknowledged. First, the preliminary relationships observed in our earlier analysis provided the basis of the more definitive path analysis and hypotheses testing described in this study. Second, path analysis, by its very nature, is often a hybrid between hypothesis testing and hypothesis confirmation (Mintz and Dixon 1997). Therefore, although we started our analysis with a specific conceptual model of pathways to MDD, subtle variations from this initial model were also critically examined, as described. In general, such models and paths are better assessed on the biological plausibility of their findings rather than mere statistical possibility. Direction of causality may be inferred but not definitively determined with this design. Caution is needed in interpreting cross-sectional data in diseases with a longitudinal course (Kraemer et al. 2000). The models examined in our study and the principal path- ways elucidated are consistent with established neurobiological and clinical correlates of late-life mood disorders and provide early insights into the medical and neurobiological basis of mood disorders. Finally, we would like to comment on the power of our analysis. A sample size of $n=100$ is usually recommended for the kind of analysis performed in our study (Bollen 1989). Although our sample size $(n=81)$ is a bit smaller than traditionally recommended, the goodness-of-fit $\chi^{2}$ is small in our analyses and the parameters are many times larger than the standard error. These caveats indicate that our sample size was adequate and the power sufficient to detect our findings.

The etiology of mood disorders in the elderly is multifactorial, and biological injury as well as psychosocial stressors may contribute to the clinical manifestations commonly observed in practice. Our data indicating that there are relatively distinct pathways that lead from underlying medical/biological substrates to MDD may have important implications for the primary and possibly secondary prevention of behavioral disorders in the elderly. Early diagnosis and aggressive management of medical illness could play an important role in reducing psychiatric morbidity in this vulnerable segment of the population. Judicious medical management could be complementary to treatment with antidepressants that remains the primary focus of pharmacological intervention in patients with significant mood disorders.

\section{ACKNOWLEDGMENTS}

Supported by NIMH grants MH 55115 and MH61567 (AK) and NIMH grant MH 52129 (Clinical Research Center for Depression in Late Life). Presented in Part at the Annual Meeting of the Society for Neuroscience, New Orleans, Oct 2000

\section{STATISTICAL ENDNOTE}

The statistical methodology of path analysis remains relatively unfamiliar in the neurosciences. It is an extension of regression analysis that attempts to separate causal influences among a set of variables into direct and indirect (or mediating) pathways. Path analysis makes it possible to model more complex systems than is possible with usual multiple regression models that include only a single dependent variable. Path models typically include intervening variables, often at multiple causal levels, and may omit paths presumed to be irrelevant. Using the methods of structural equation modeling (SEM), overall evaluation of an entire postulated system of causal relations is possible.

Multiple logistic regression analysis, as employed in a previous report of this study (Kumar et al. 2000), evaluates the significance of direct associations from a set of predictor variables to the occurrence of depression. Path analy- 
sis, as employed in this report, makes it possible to simultaneously evaluate the statistical plausibility of the entire set of posited causal relationships. As depicted in the main Figure 1, this is a multilevel model that includes both direct and indirect causal paths. The goodness-of-fit $\chi^{2}$ tests the deviation of the data from the model. When significant, it indicates that the data do not fit the posited causal model. Thus, a nonsignificant goodness-of-fit $\chi^{2}$ is desirable, in that it indicates that the posited causal model is statistically plausible in light of the observed data. Of course, the fact that a model is plausible does not guarantee that it is correct. It is not at all uncommon for several alternative models to "fit" the data (as occurred in this case).

The Mplus software makes it possible to simultaneously evaluate multistage models including both continuous and dichotomous dependent variables. In the former case, the path (regression) coefficients are conventional linear regression coefficients, indicating the expected change in the dependent variable for a unit change in the independent variable. In the case of dichotomous dependent variables (e.g., depression in the current analyses), the coefficients are probit coefficients. As such, they represent the change in the probability of "caseness" associated with a unit change in the independent variable. The model underlying the probit portion of the analysis is that the likelihood of observing the outcome (depression in this case) is based on one's position on a hypothetical, unobserved normal curve. The probit equation estimates a linear combination of predictors to predict the z-score representing one's position on that curve and thus the probability of being a case.

\section{REFERENCES}

Alexopoulos GS, Meyers BS, Young RC, Mattis S, Kakuma T (1993): The course of geriatric depression with "reversible dementia": A controlled study. Am J Psychiatry 150:1693-1699

Alexopoulos GS, Meyers BS, Young RC, Kakuma T, Silbersweig D, Charlson M (1997): Clinically defined vascular depression. Am J Psychiatry 154:562-565

Alexopoulos GS, Meyers BS, Young RC, Kalayam B, Kakuma T, Gabrielle M, Sirey JA, Hull J (2000): Executive dysfunction and long-term outcomes of geriatric depression. Arch Gen Psychiatry 57:285-290

American Heart Association (1990): Stroke Risk Factor Prediction Chart. Dallas, American Heart Association

American Psychiatric Association (1994): Diagnostic and Statistical Manual of Mental Disorders (4th Edition). Washington, DC, American Psychiatric Press

Awad IA, Spetzler RF, Hodak JA, Awad CA, Carey R (1986): Incidental subcortical lesions identified on magnetic resonance imaging in the elderly. I. Correlation with age and cerebrovascular risk factors. Stroke 17:1084-1089

Blazer D, Hughes DC, George LK (1987): The epidemiology of depression in an elderly community population. Gerontologist 27:281-287
Bollen KA (1989): Structural Equations with Latent Variables. New York, John Wiley \& Sons

Borson S, Claypoole K, McDonald G (1998): Depression and chronic obstructive pulmonary disease: Treatment trials. Seminars in Clinical Neuropsychiatry 3:115-130

Braffman BH, Zimmerman RA, Trojanowski JQ, Gonatas NK, Hickey WF, Schlaepfer WW (1988): Brain MR: Pathologic correlation with gross and histopathology. 1. Lacunar infarction and Virchow-Robin spaces. 2. Hyperintense whitematter foci in the elderly. Am J Roentgenol 151:551-558

Caine ED, Lyness JM, King DA (1993): Reconsidering depression in the elderly. Am J Geriatr Psychiatry 1:4-20

Coffey CE, Wilkinson WE, Weiner RD, Parashos IA, Djang WT, Webb MC, Figiel GS, Spritzer CE (1993): Quantitative cerebral anatomy in depression. A controlled magnetic resonance imaging study. Arch Gen Psychiatry 50:7-16

Coulehan JL, Schulberg HC, Block MR, Janosky JE, Arena VC (1990): Medical comorbidity of major depressive disorder in a primary medical practice. Arch Intern Med 150:2363-2367

Cowell PE, Turetsky BI, Gur RC, Grossman RI, Shtasel DL, Gur RE (1994): Sex differences in aging of the human frontal and temporal lobes. J Neurosci 14:4748-4755

Drayer BP (1988): Imaging of the aging brain. Part I. Normal findings. Part II. Pathologic conditions. Radiology 166: 785-796

Duman RS, Charney DS (1999): Cell atrophy and loss in major depression. Biol Psychiatry 45:1083-1084

Emery VO, Oxman TE (1992): Update on the dementia spectrum of depression. Am J Psychiatry 149:305-317

Folstein MF, Folstein SE, McHugh PR (1975): “Mini-mental state." A practical method for grading the cognitive state of patients for the clinician. J Psychiatr Res 12:189-198

Frasure-Smith N, Lesperance F, Talajic M (1995): Depression and 18-month prognosis after myocardial infarction [published erratum appears in Circulation 1998 Feb 24:708]. Circulation 91:999-1005

Gierz M, Jeste DV (1993): Physical comorbitidy in elderly schizophrenic and depressed patients. Am J Geriatr Psychiatry 1:165-170

Gould E, Tanapat P, McEwen BS, Flugge G, Fuchs E (1998): Proliferation of granule cell precursors in the dentate gyrus of adult monkeys is diminished by stress. Proc Natl Acad Sci USA 95:3168-3171

Hamilton M (1967): Development of a rating scale for primary depressive illness. Br J Soc Clin Psychol 6:278-296

Henderson AS, Korten AE, Jacomb PA, Mackinnon AJ, Jorm AF, Christensen H, Rodgers B (1997): The course of depression in the elderly: A longitudinal communitybased study in Australia. Psychol Med 27:119-129

Hickie I, Scott E (1998): Late-onset depressive disorders: A preventable variant of cerebrovascular disease? Psychol Med 28:1007-1013

Katz IR (1996): On the inseparability of mental and physical health in aged persons: Lessons from depression and medical comorbidity. Am J Geriatr Psychiatry 4:1-16

Katz IR, Striem J, Parmelee P (1994): Psychiatric-medical comorbidity: Implications for health services delivery and for research on depression. Biol Psychiatry 36:141-145 
Kraemer HC, Yesavage JA, Taylor JL, Kupfer D (2000): How can we learn about developmental processes from crosssectional studies, or can we? Am J Psychiatry 157:163-171

Krishnan KR (1993): Neuroanatomic substrates of depression in the elderly. J Geriatr Psychiatry Neurol 6:39-58

Krishnan KR, Hays JC, Blazer DG (1997): MRI-defined vascular depression. Am J Psychiatry 154:497-501

Kumar A, Miller D, Ewbank D, Yousem D, Newberg A, Samuels S, Cowell P, Gottlieb G (1997a): Quantitative anatomic measures and comorbid medical illness in late-life major depression. Am J Geriatr Psychiatry 5:15-25

Kumar A, Schweizer E, Jin Z, Miller D, Bilker W, Swan LL, Gottlieb G (1997b): Neuroanatomical substrates of latelife minor depression. A quantitative magnetic resonance imaging study. Arch Neurol 54:613-617

Kumar A, Jin Z, Bilker W, Udupa J, Gottlieb G (1998): Lateonset minor and major depression: Early evidence for common neuroanatomical substrates detected by using MRI. Proc Natl Acad Sci USA 95:7654-7658

Kumar A, Bilker W, Jin A (2000): Atrophy and high intensity lesions: Complementary neurobiological mechanisms in late-life major depression. Neuropsychopharmacology 22:264-274

Lacro JP, Jeste DV (1994): Physical comorbidity and polypharmacy in older psychiatric patients. Biol Psychiatry 36:146-152

Lai TJ, Payne ME, Byrum CE, Steffens DC, Krishnan KR (2000): Reduction of orbital frontal cortex volume in geriatric depression. Biol Psychiatry 48:971-975

Linn BS, Linn MW, Gurel L (1968): Cumulative illness rating scale. J Am Geriatr Soc 16:622-626

Lopez JF, Chalmers DT, Little KY, Watson SJ (1998): A.E. Bennett Research Award. Regulation of serotonin1A, glucocorticoid, and mineralocorticoid receptor in rat and human hippocampus: Implications for the neurobiology of depression. Biol Psychiatry 43:547-573

Lustman PJ, Griffith LS, Gavard JA, Clouse RE (1992): Depression in adults with diabetes. Diabetes Care 15:1631-1639

Lyness JM, Caine ED, Cox C, King DA, Conwell Y, Olivares $\mathrm{T}$ (1998): Cerebrovascular risk factors and later-life major depression. Testing a small-vessel brain disease model. Am J Geriatr Psychiatry 6:5-13

Mintz J, Dixon W (1997): Objection overruled: A comment on Gastwirth, Krieger, and Rosenbaum. American Statistician 51:117-119

Morris P, Rapoport SI (1990): Neuroimaging and affective disorder in late life: A review. Can J Psychiatry 35:347-354

Muthen B (1984): A general structural equation model with dichotomous, ordered categorical, and continuous latent variable indicators. Psychometrika 49:115-132

National Institutes of Health (1992): NIH consensus conference. Diagnosis and treatment of depression in late life. JAMA 268:1018-1024

O'Brien J, Desmond P, Ames D, Schweitzer I, Harrigan S, Tress B (1996): A magnetic resonance imaging study of white matter lesions in depression and Alzheimer's disease [published erratum appears in Br J Psychiatry 1996 168:792]. Br J Psychiatry 168:477-485

Parmalee PA, Katz IR, Lawton MP (1992): Incidence of depression in long term care settings. J Gerontol 47:M189-M196
Penninx BW, Geerlings SW, Deeg DJ, van Eijk JT, van Tilburg W, Beekman AT (1999): Minor and major depression and the risk of death in older persons. Arch Gen Psychiatry 56:889-895

Rabins PV, Pearlson GD, Aylward E, Kumar AJ, Dowell K (1991): Cortical magnetic resonance imaging changes in elderly inpatients with major depression. Am J Psychiatry 148:617-620

Rajkowska G (2000): Postmortem studies in mood disorders indicate altered numbers of neurons and glial cells. Biol Psychiatry 48:766-777

Rajkowska G, Miguel-Hidalgo JJ, Wei J, Dilley G, Pittman SD, Meltzer HY, Overholser JC, Roth BL, Stockmeier CA (1999): Morphometric evidence for neuronal and glial prefrontal cell pathology in major depression. Biol Psychiatry 45:1085-1098

Sapolsky RM, Pulsinelli WA (1985): Glucocorticoids potentiate ischemic injury to neurons: Therapeutic implications. Science 229:1397-1400

Sato R, Bryan RN, Fried LP (1999): Neuroanatomic and functional correlates of depressed mood: the Cardiovascular Health Study. Am J Epidemiol 150:919-929

Sheline YI (2000): 3D MRI studies of neuroanatomic changes in unipolar major depression: The role of stress and medical comorbidity. Biol Psychiatry 48:791-800

Sheline YI, Wang PW, Gado MH, Csernansky JG, Vannier MW (1996): Hippocampal atrophy in recurrent major depression. Proc Natl Acad Sci USA 93:3908-3913

Spangler KM, Challa VR, Moody DM, Bell MA (1994): Arteriolar tortuosity of the white matter in aging and hypertension. A microradiographic study. J Neuropathol Exp Neurol 53:22-26

Steffens DC, Helms MJ, Krishnan KR, Burke GL (1999): Cerebrovascular disease and depression symptoms in the Cardiovascular Health Study. Stroke 30:2159-2166

Stewart AL, Greenfield S, Hays RD, Wells K, Rogers WH, Berry SD, McGlynn EA, Ware JE Jr (1989): Functional status and well-being of patients with chronic conditions. Results from the Medical Outcomes Study. JAMA 262:907-913

Udupa J, Samarasekera S (1996): Fuzzy connectedness and object definition: theory, algorithms, and applications in image segmentation. Graphical Models and Image Processing 58:246-261

Unutzer J, Patrick DL, Simon G, Grembowski D, Walker E, Rutter C, Katon W (1997): Depressive symptoms and the cost of health services in HMO patients aged 65 years and older. A 4-year prospective study. JAMA 277:1618-1623

Wells KB, Stewart A, Hays RD (1989): The functioning and well-being of depressed patients: Results from the Medical Outcomes Study. JAMA 277:1618-1623

Wolf PA, D'Agostino RB, Belanger AJ, Kannel WB (1991): Probability of stroke: A risk profile from the Framingham Study. Stroke 22:312-318

Ylikoski A, Erkinjuntti T, Raininko R, Sarna S, Sulkava R, Tilvis R (1995): White matter hyperintensities on MRI in the neurologically nondiseased elderly. Analysis of cohorts of consecutive subjects aged 55 to 85 years living at home. Stroke 26:1171-1177

Zubenko GS, Marino LJ Jr, Sweet RA, Rifai AH, Mulsant BH, Pasternak RE (1997): Medical comorbidity in elderly psychiatric inpatients. Biol Psychiatry 41:724-736 